\title{
Noções Jntrodutórias sobre a Função-Avatar e o Hiperdiscurso
}

Introductory Notion on the Avatar Function and Hiperdiscourse

\section{Carme Regina SCHONS* Mário Fafael Yudi FUKUE**}

Resumo: Estudamos o funcionamento da função-avatar na perspectiva discursiva. Abordamos conceitos como hipertexto, hiperdiscurso, funçãoautor e silenciamento. A função-avatar possibilita estudar autoria em sites institucionais, como blogs e comunidades virtuais, espaços em que os autores pouco diferem de outras modalidades midiáticas, pois até mesmo os discursos "anônimos" carregam assinatura de um nickname - o Avatar, trazem assinatura da própria instituição. No hipertexto, gênero entrelaçado por textos interconectados por links, determinados por um design que orienta quais sites acessar, há intervenção de internautas.

Palavras-chave: Função-autor. Hiperdiscurso. Silenciamento.

Abstract: This text studies the functioning of the avatar-function in the discursive perspective. It approaches concepts such as hypertext, hiperdiscourse, autor-function and silencing. The avatar-function enables to study the authorship in institutional sites such as blogs and virtual communities, spaces in which the authors slightly differ from other mediatic modalities, for even the "anonymous" discourses carry a nickname as a signature - the Avatar, bringing the signature of the institution itself. In the hypertext, interlaced genre by texts interconnected by links, determined by a design which guides to sites to be accessed, there is an intervention by internauts. Key-words: Author-function. Hiperdiscourse. Silencing.

* Doutorado em Letras pela Universidade Federal do Rio Grande do Sul (2006). Professora do Mestrado e do Curso de Letras da Universidade de Passo Fundo. Contato: crschons@gmail.com.

** Mestre em Letras, Estudos Linguísticos, pela Universidade de Passo Fundo (UPF). Contato: rafaelfukue@yahoo.com. 


\section{Introdução}

A questão comum posta pela análise do discurso é a relação língua e sujeito. O modo como o estudo sobre língua se materializa na ciência reflete os problemas de tratamento textual - processo que envolve cultura e política. Se essa é uma relação comum, é também com os meios teóricos de respondê-la que procuramos contribuir com este estudo. O texto é uma peça de linguagem que representa uma unidade significativa; é um objeto sócio-histórico, onde o sujeito, ao produzir sentido, se produz, ou melhor, o sujeito se constitui, produzindo sentido. Portanto, a história do sujeito e a história dos sentidos são inseparáveis em um texto. Assim, a proposta deste artigo é traçar um breve percurso do funcionamento da função-avatar no tratamento da questão da autoria na perspectiva da AD.

A nomeação de função-avatar surgiu da necessidade de formar um aparato teórico-analítico que pudesse dar conta de lidar com produções em espaços eletrônicos. Fukue (2011), em sua pesquisa de mestrado, analisa discursividades sobre transtorno bipolar de humor presentes em blogs e comunidades virtuais e, em sua proposta, para discutir a questão da autoria em sites institucionais, observa que estes não diferem muito de outras modalidades midiáticas institucionais, tendo em vista que até mesmo os discursos "anônimos" carregam assinatura de um indivíduo nickname - uma espécie de Avatar -, mas que ocupa o lugar de função-autor ou carrega consigo a assinatura da própria instituição.

A internet é espaço institucional no qual, ao contrário da aparente liberdade, o sujeito se encontra "submetido a leis, normas e relações de poder”, como postula Foucault (2007, p. 68). Nessa composição, as articulações realizadas por uma função-autor produzem, sob as determinações da interpelação ideológica, efeitos de memória coletiva. Isso permite estabelecer um diálogo com Pêcheux (1997), para quem desde a Idade Média os aparelhos do poder de nossa sociedade geram a memória coletiva e a divisão social do trabalho de leitura, ou seja,

começou no meio dos clérigos, entre alguns deles, autorizados a ler, falar e escrever em seus nomes (logo, portadores de uma leitura e de uma obra própria) e o conjunto de todos os outros, cujos gestos incansavelmente repetidos (de cópia, transcrição, extração, classificação, indexação, codificação, etc.) constituem também uma leitura, mas uma 
leitura impondo ao sujeito-leitor seu apagamento atrás da instituição que o emprega: o grande número de escrivão, copistas e "contínuos", particulares e públicos, se constituiu, através da Era Clássica e até nossos dias, sobre esta renúncia a toda pretensão de "originalidade", sobre este apagamento de si na prática silenciosa de uma leitura consagrada ao serviço de uma Igreja, de um rei, de um Estado, ou de uma empresa. (PÊCHEUX, 1997, p. 57 - grifos do autor).

É possível considerar tal apagamento de si na prática silenciosa de uma leitura a serviço de um dizer institucional o funcionamento da função-autor no hipertexto. O hipertexto é um formato textual entrelaçado por vários textos interconectados por links, passíveis de intervenção de internautas, determinados por um design que orienta e recomenda quais sites se devem/podem acessar.

De acordo com Cazarin (2011, p. 237), no hipertexto "o sujeito-leitor aciona uma rede por meio de links que lhe são oferecidos”. Ao deslocar a perspectiva de leitura para o âmbito do hipertexto, a autora afirma que "o fato de este extrapolar a linearidade e se apresentar numa dimensão que possibilita ao sujeito a escolha de diferentes caminhos a seguir, à primeira vista, pode sugerir que o sujeito-leitor tenha domínio pleno de suas escolhas, de suas intenções" (CAZARIN, 2011, p. 241).

A noção de hipertexto institui um espaço teórico e metodológico e a sua forma material nos leva a pensar sentido como uma relação da língua e do sujeito com a história. É a existência dessas duas materialidades - linguística e histórica - que nos permite um gesto de leitura sobre a reversibilidade do papel do sujeito no hiperdiscurso ${ }^{1}$, porque atravessa e é atravessado por vários discursos interconectados e não é imune à nova ordem social da qual passa a fazer parte.

Para desenvolver nossa reflexão é necessário abordarmos, mesmo que de maneira sucinta, alguns conceitos caros à nossa proposta, como hipertexto, hiperdiscurso, função-avatar e silenciamento.

\section{Hipertexto em Ato e Hipertexto em Potência}

O advento da internet e sua crescente universalização propiciaram o

${ }^{1}$ Esta noção do sujeito no ciberespaço será desenvolvida na seção 2. 
surgimento de uma superfície textual eletrônica organizada em uma espécie de rede de associações. A este tipo de materialidade textual se convencionou chamar de "hipertexto", que permite uma leitura não linear justamente por organizar as informações (blocos textuais) por associação.

Conforme Lévy (1993), o hipertexto destaca-se de outras materialidades textuais pelas seguintes características:

a) Totalidade: o hipertexto reúne a totalidade das informações eletrônicas da Internet. Podemos considerar a World Wide Web um imenso hipertexto, com todos os blocos de informações interligados;

b) Associação: no hipertexto, as informações são organizadas por associação. Por isso, a forma geométrica que melhor ilustra o hipertexto é a rede multidimensional, na qual cada nó representa a emergência de uma associação entre dois ou mais blocos de informações;

c) Leitura não linear e links: Os nós constituem a porção de texto que emerge como algo a ser lido na tela do computador. $\mathrm{O}$ internauta pode passar de um bloco textual a outro navegando pelos links, que permitem a relação entre esses nós. O link é a grande marca do hipertexto, pois permite que as associações entre diferentes blocos textuais sejam navegáveis, assim como interliga todos os blocos;

d) É a atividade do internauta que faz o sistema ser um hipertexto. Acessar um site sem explorar algum de seus links não difere muito de ler um texto impresso. O hipertexto é tão determinado quanto qualquer outra modalidade midiática.

O hipertexto é o mundo de significação, no qual "os atores da comunicação ou os elementos de uma mensagem constroem e modelam universos de sentidos" (LÉVY, 1993, p. 25). Assim, é a navegação efetuada pelo sujeito que constrói um hipertexto ${ }^{2}$. Por meio da seleção de links, o internauta visita e lê pedaços de textos de diferentes blocos textuais da internet,

${ }^{2}$ Conforme Lévy (1993, p. 29), "[Theodore] Nelson inventou o termo para exprimir a idéia de escrita/leitura não linear em um sistema de informática". Antes de Nelson, Vannevar Bush já havia proposto criar um banco de dados, o Memory Extender, que classificaria e selecionaria informações por meio da associação, não por hierarquização (LÉVY, 1993, p. 28). 
reunindo-os em algo que podemos chamar de "hipertexto em ato". Dessa forma, fazemos a distinção entre "hipertexto em ato" e algo que denominamos de "hipertexto em potência", que reúne totalidade de textos da web.

A esse respeito, Fukue (2011, p. 99) escreve:

Ao acessar a internet, o internauta é potencialmente capaz de acessar qualquer site livre da internet. Sites privados, como intranets de universidades e empresas, podem ser acessados mediante a posse de senha de acesso. Dessa forma, a internet constitui-se num imenso hipertexto em potencial. Por outro lado, ao escolher um site, blog ou link, o internauta deixa de acessar todos os outros. Mesmo que fosse possível acessar todos os links da internet, o percurso denota a escolha consciente ou não do internauta. Por essa razão, o hipertexto em ato é produto da ação dos "atores de comunicação", que constroem e modelam universos de sentido.

O hipertexto evidencia a interpenetração entre leitura e escrita, uma vez que o processo da escrita projeta sempre um leitor e a escrita só produz sentido a partir da função autoria, a partir de gestos de interpretação. Segundo Lévy (1996, p. 46), todo aquele que constrói o hipertex to “já é um leitor. [...] quem atualiza um percurso [...] contribui para a redação, conclui momentaneamente uma escrita interminável [...]. A partir do hipertexto, toda leitura tornou-se um ato de escrita".

Apesar do entusiasmo de muitos estudiosos, o hipertexto não é algo extraordinário, pois a determinação que os sujeitos sofrem no ciberespaço é a mesma de outros textos; da mesma forma, não está livre dos efeitos que o sujeito sofre, visto que a ideologia e o inconsciente continuam vivos nos sujeitos que navegam no ciberespaço. Conforme Castells (2003, p. 225), conflitos sociais fora da web estão presentes no ciberespaço.

O ciberespaço é uma teia de relacionamentos entre indivíduos e hipertextos. Além disso, cremos que o ciberespaço acentua a ilusão de ser um lugar discursivo com menos mecanismos de coerção e exclusão do que outras modalidades discursivas. Num blog ou comunidade virtual, por exemplo, não há a necessidade de o sujeito-autor assinar um post ou comentário. Dessa forma, por não precisar se responsabilizar socialmente pelo seu dizer, o indivíduo sente-se livre para escrever aquilo que, talvez, 
não expressaria pessoalmente, pois encontra no ciberespaço "um lugar de dizer que não é controlado, regulado pelas diferentes instâncias sociais, como é o caso da escola, e da nossa sociedade letrada como um todo" (GRIGOLETTTO, 2009, p. 8).

Deslocando a perspectiva discursiva de leitura para o âmbito do hipertexto, podemos dizer que o fato de extrapolar a linearidade e se apresentar numa dimensão de liberdade para sujeito, o efeito de um imaginário sobre o lugar social em que se inscreve (tanto o sujeito-autor quanto o sujeito-leitor) interfere nos gestos de interpretação na escolha do(s) link(s). O disperso e o heterogêneo constituem os processos de leitura e de escritura, aparentemente livres, sofrem efeitos de determinações históricas, ideológicas e sociais, porque, por trás da atividade do internauta, existe um design informacional que, de certa maneira, orienta o campo de possibilidades que um hipertexto abre para o usuário. Ao acessar um site, por exemplo, o internauta já recebe uma interface com links possíveis de serem acessados ou uma lista de sites recomendados para aprofundamento de um tema. Não é só por isso. Aqui joga também a determinação histórica do autor e do leitor.

É a essa faceta discursiva, pretensamente livre das amarras institucionais do hipertexto, que designamos de hiperdiscurso, assunto da próxima seção.

\section{A Relação Hiperdiscurso e Sujeito no Ciberespaço}

Reiteramos que reconhecemos o papel sempre presente da ideologia e do inconsciente em qualquer discurso, inclusive do hiperdiscurso. No entanto, o hiperdiscurso é afetado por características próprias da cibercultura. Dessa forma, é resultado da interconexão dos computadores e da infraestrutura material da comunicação digital, bem como constitui parte do "universal das informações sem totalidade" (LÉVY, 1999, p. 17). O hiperdiscurso é constituído de discursos de "seres que navegam no ciberespaço", que constroem a cibercultura e alimentam o hipertexto.

Precisamos, no entanto, demonstrar como se caracteriza o relacionamento entre o hipertexto e o hiperdiscurso.

Em primeiro lugar, o hipertexto evidencia a interpenetração entre leitura e escrita, uma vez que o processo da escrita projeta sempre um leitor, e a escrita só produz sentido a partir da leitura. Segundo Lévy (1996, p. 46), todo aquele que constrói o hipertexto “já é um leitor. [...] quem atualiza um 
percurso [...] contribui para a redação, conclui momentaneamente uma escrita interminável. Nesse sentido, é possível reconhecer uma autoria coletiva no hipertexto (GRIGOLETTO; JOBIM, 2007, p. 9). Essa leitura-escrita do hipertexto não ocorre sem a interpelação ideológica e o afetamento da ordem do inconsciente sobre o sujeito-leitor-autor, ou, se for possível dizer, sobre o hipersujeito. Dessa forma, a cada link escrito ou escolhido (visualizado), a cada palavra publicada ou lida, há sempre o trabalho da ideologia e do inconsciente, que afetam o hipersujeito e o hiperdiscurso. Decorre disso que a autoria coletiva é também afetamento coletivo.

Em segundo lugar, o hiperdiscurso caracteriza-se, mais do que qualquer outro tipo de discurso, pela ilusão de liberdade que o ciberespaço propicia pela possibilidade do uso de avatares e do anonimato ${ }^{3}$. Assim, cremos que o ciberespaço acentua a ilusão de liberdade, na qual o hipersujeito pensa estar livre das amarras institucionais. De certa forma, o hiperdiscurso sofre menos mecanismos de controle e exclusão do que outras modalidades discursivas.

Para compreender como ocorrem os processos de constituição do hiperdiscurso, precisamos entender os conceitos de interdiscurso e de formação discursiva. Inicialmente, buscamos a obra Semântica e discurso, onde Pêcheux propõe o conceito de interdiscurso para definir " o 'todo complexo com dominante' das formações discursivas, afirmando que também ele é submetido à lei de desigualdade-contradição-subordinação que, caracteriza o complexo das formações ideológicas" (PÊCHEUX, 1995, p. 162). O interdiscurso é constituinte de todos os discursos, "é todo um conjunto de formulações feitas” (ORLANDI, 2007a, p. 33), pois não há origem do dizer, tudo que é enunciado sempre resulta dos discursos dispersos e já proferidos em algum lugar.

Podemos, portanto, afirmar que o hiperdiscurso faz parte da rede de discursos de internautas e estabelece uma relação de dependência com o interdiscurso. Posto de outra forma, mesmo pretensamente livre de amarras institucionais, o hiperdiscurso é oriundo e constituinte do interdiscurso.

Quanto à rede de sentidos criada pelo interdiscurso, trabalhamos segundo o pressuposto de que o sujeito-autor, ao anunciar, identifica-se

\footnotetext{
${ }^{3} \mathrm{O}$ anonimato na internet nunca é total. Investigadores especializados em crimes cibernéticos são capazes de chegar ao autor de qualquer texto por meio do rastreamento de IP (Protocolo de Internet) e do número ID do computador.
} 
com uma dada posição discursiva e nos dá condições de observar dois processos discursivos: o parafrástico e o polissêmico. Em blogs e comunidades virtuais, por exemplo, é possível o sujeito-autor se esconder atrás do anonimato ou de um nickname. É neste ponto da discussão, que introduzimos a noção de função-avatar, o sujeito-autor que, para se ver livre de amarras institucionais e seus sistemas de controle, utiliza-se de um Avatar (o anonimato ou o nickname), que o substitui no ciberespaço.

A função-avatar dá condições de o sujeito construir sua discursividade, marcada pela possibilidade de dizer e escrever a fantasia que lhe é interditada na realidade, preservando as faces de todos os autores-leitores. Nesse sentido, vale lembrar que a liberdade/fuga que a função-avatar proporciona nunca é total (FUKUE, 2011). Ocupando a posição de função-avatar, o hipersujeito está sempre afetado pela ideologia e pelo inconsciente. Tanto a função-autor como a função-avatar ${ }^{4}$ são afetadas pelos conflitos ideológicos que habitam dada formação discursiva e pelas condições de produção do discurso.

A pretensa liberdade do hiperdiscurso facilita a saturação do discurso-um pelo(s) discurso(s)-outro(s). A negação dos dizeres e do pré-construído do discurso-outro, o uso do discurso relatado indireto e o silenciamento parecem ocorrer liv remente na função-avatar. Nessa ilusão de liberdade, o interdito parece estar interditado e as lacunas, preenchidas. Porém, é preciso frisar sempre: tudo é ilusão. A função-avatar e o hiperdiscurso ocorrem sob efeito da ilusão de liberdade que o hipertexto e a cibercultura podem proporcionar (FUKUE, 2011).

Diante de tudo o que foi posto, é necessário frisar que não podemos reduzir o hipertexto à simples materialidade linguística do hiperdiscurso. $\mathrm{Na}$ verdade, com o conceito de hiperdiscurso procuramos designar apenas a parte do hipertexto pretensamente livre de amarras institucionais, como blogs pessoais e comunidades virtuais que não estão atreladas a nenhuma instituição, a não ser à própria internet. Dessa forma, as discursividades produzidas em sites oficiais e/ou institucionais sofrem a mesma coerção e controle de discursos institucionais não eletrônicos. É somente a parte pretensamente livre do hipertexto que constitui a materialidade linguística do hiperdiscurso (FUKUE, 2011).

${ }^{4}$ Retomaremos a discussão sobre função-avatar na próxima seção. 


\section{Função-avatar: o silenciamento de si no hiperdiscurso}

Nesta seção, detalharemos o conceito proposto por este artigo: $a$ função-avatar. Antes, é necessário reconhecer e pagar tributo ao conceito de autoria de Foucault, trabalhado posteriormente por Pêcheux e repensado por Orlandi.

Conforme Orlandi (1996, p. 97), "o que caracteriza a autoria é a produção de um gesto de interpretação", que acontece porque "o espaço simbólico é marcado pela incompletude, pela relação com o silêncio. A interpretação é o vestígio do possível" (ORLANDI, 1996, p. 18). Ao interpretar/ser autor, o sujeito relaciona-se com o mundo pela linguagem. Em termos lacanianos, o autor tenta atingir a completude com a língua e, por esse processo, o sujeito-autor torna-se, ele mesmo, significante. Conforme Orlandi (2001, p. 22), "o sujeito é interpretação, fazendo significar, ele significa" e "autoria [...] constrói e é construída pela interpretação".

O processo de autoria move-se entre o dito e o silenciado. Ao dizer, o sujeito-autor silencia outros dizeres possíveis. Por isso, "conduzir uma escrita depende, sim, de um olhar, [...] o reconhecimento ou esquecimento depende do trabalho de um sujeito-autor" (Schons, 2005, p. 146).

O reconhecimento (dito) e o esquecimento (silenciado) revelam o funcionamento dos mecanismos de controle do discurso. Conforme Foucault em $A$ ordem do discurso, todo discurso é produzido mediante mecanismos que o controlam e o limitam. Foucault (1999) aponta para a existência de procedimentos externos ao discurso, que excluem e interditam dizeres, e procedimentos internos, que impõem coerções ao discurso, tais como comentários, autoria e a disciplina científica à qual o discurso se filia.

A autoria agrupa e limita o discurso, conferindo-lhe unidade e originalidade, sob o efeito de ser "origem do dizer" (esquecimento 1), que é construído pelo ato de assinar. Ao se revelar autor, o indivíduo na função-autor torna-se responsável pelo que diz, responde por isso e submete-se ao jogo de reconhecimento e esquecimento de saberes.

A função-autor obedece aos mecanismos de exclusão de discursos. Ele está sujeito às leis do ritual, da doutrina e da disciplina (FOUCAULT, 1999). Por exemplo, quando um médico psiquiatra assina o artigo do site da Associação Brasileira do Transtorno Bipolar, é coagido a escrever somente o que a psiquiatria, enquanto disciplina (e por que não dizer doutrina), permite. Qualquer outro dizer é obrigatoriamente silenciado. Percebe-se, dessa forma, 
que pela função-autor instaura-se o controle da produção de discursos. Dessa forma, a função-autor não denota um indivíduo empírico (ou o sujeito jurídico), mas relaciona-se com o funcionamento dos indivíduos, enquanto sujeitos afetados pela ideologia e pelo inconsciente. Por essa razão, a função-autor também está subjugada pelas forças da interpelação e pelo afetamento.

No tocante aos mecanismos de exclusão e função-autor, sites institucionais não diferem muito de outras modalidades midiáticas institucionais, pois qualquer instrumento institucional carrega a assinatura de um indivíduo que exerce a função-autor e ocupa do autor ou da instituição, pela assinatura. Não há discursos "anônimos". Dessa forma, em site institucionais pela função-autor se produz o efeito-texto pelo efeito de fechamento que confere ao seu discurso. É o efeito de "um" enunciado como um todo (GALLO, 1994).

Por outro lado, blogs e comunidades virtuais possibilitam a produção de discursos "anônimos", sem assinatura. Reconhecemos que a escrita dos blogs é um exemplo em que a função-autor é coletiva: os leitores, ao comentar os textos, "tornam-se também autores, que podem representar lugares sociais diferentes" (GRIGOLETTO, 2009, p. 7). No entanto, em nosso ver, há algo que ultrapassa a barreira da autoria coletiva. Em blogs e comunidades virtuais, é possível ao sujeito-autor se esconder atrás do anonimato ou de um nickname. Podemos nomear de função-autor-avatar, ou simplesmente função-avatar, a esse sujeito-autor que, para se ver livre de amarras institucionais e seus sistemas de controle, utiliza-se de um Avatar (o anonimato ou o nickname) que o substitui no ciberespaço.

É, pois, acerca do funcionamento da função-avatar que queremos propor uma relação entre o silenciamento do nome e a autocensura.

Partindo do proposto por Fukue (2011, p. 102) de que a função-avatar é mais do que um simples pseudônimo literário, mas é a existência pretensamente livre de um sujeito-autor no ciberespaço, em que a constituição de sua identidade se move, basicamente, pela virtualidade, pela liberdade e pela autoria. De acordo com o autor, "no mundo da informática, o termo avatar significa a representação gráfica de um utilizador em realidade virtual. O termo ganhou as ruas com a popularização do jogo Second Life, um universo virtual no qual qualquer indivíduo pode criar uma representação virtual de si mesmo (um avatar) para viver neste mundo eletrônico" (FUKUE, 2011, p. 102). 
A função-avatar aproveita-se daquilo que é do permanente e tenso deslocamento, que cria condições no ciberespaço "para que o sujeito construa a sua discursividade na fugacidade, também marcada pela possibilidade de dizer e escrever, na tela, a fantasia que lhe é interditada na realidade" (ROMÃO apud GRIGOLETTTO, 2009, p. 7).

Um ponto que gostaríamos de trazer para pensar tal função do sujeito é a noção de autocensura. Se considerarmos que o processo de autoria se move entre o dito e o silenciado, conforme afirmamos acima, o reconhecimento (dito) e o esquecimento (silenciado) revelam o funcionamento dos mecanismos de controle de um discurso, que, de acordo com Foucault, controlam e geram a interdição do próprio discurso (comentários, críticas, justificativas), não apenas correções, nem meros esquecimentos, e, sim, uma censura do próprio dizer.

Ao tratar da função-autoria nos blogs sobre a bipolaridade, Fukue afirma que, de certa maneira, a função-avatar é resultado da tentativa do sujeito de concretizar o desejo de ser "outro", de assumir uma identidade diferente. Esse mecanismo revela a busca do sujeito pela completude, a perseguição de seu "eu ideal". Nota-se que a função-avatar é determinada pelas condições de produção desta época, neste caso, a cibercultura. É a cultura do ciberespaço que torna possível a emergência eletrônica de outro "eu", representada pelo avatar, que, ao escrever em blogs e outros espaços eletrônicos, assume o papel de função-avatar. Em suma, a função-avatar é resultado da interelação entre o sujeito-autor e a cibercultura, enquanto condição de produção de discurso.

Logo, a liberdade/fuga que a função-avatar proporciona nunca é total. Ocupando a posição de função-autor ou função-avatar. A liberdade total, assim como o gozo total, é impraticável, pois atingir a completude é deixar de ser significante. No discurso há sempre um resto, uma falha, há sempre algo-lá que amarra o sujeito e afeta seu discurso.

Conforme Orlandi (1996b, p. 69), na AD a "função-autor [e aqui incluímos a função-avatar] não se limita como em Foucault, a um quadro restrito e privilegiado de produtores 'originais' de linguagem [...] [assim] autor é aquele que responde pelo que diz ou escreve, pois é suposto estar em sua origem". Vale dizer, também, que Gallo (2008) distingue a função-autor do efeito-autor. O efeito-autor evidencia-se em uma nova FD, resultante do confronto de duas FDs. Segundo Gallo (2008), o efeito-autor fundador evidencia-se no discurso como acontecimento discursivo que funda nova FD. Nessa nova FD há uma relação direta e 
imbricada entre sua forma-sujeito e o efeito-autor fundador. Com base nas formulações de Orlandi (1996b) e de Gallo (2008), entendemos que tanto a função-autor como a função-avatar são afetadas pelos conflitos ideológicos que habitam dada formação discursiva e pelas condições de produção (a situação da enunciação, o contexto sócio-histórico e o efeito produzido pela memória discursiva).

Por que falar em uma função-avatar? Visto que a autoria sempre se configura como gesto de interpretação, é preciso reconhecer que todo processo de escrita é, concomitantemente, um processo de leitura. Há sempre uma relação simbólica entre um sujeito (que lê) e um sujeito (que escreve). Ao assumir a função-avatar, o sujeito-autor pretende ser livre para dizer "aquilo que não convém dizer" ao sujeito-leitor. Dessa forma, o sujeito-autor consegue preservar suas faces ${ }^{5}$, mesmo ameaçando as do sujeito-leitor. Ducrot diria que a função-avatar acontece no nível do locutor, lugar pelo qual o sujeito se representa como $e u$ no discurso.

Numa comunidade virtual sobre TAB temos a seguinte discursividade:

X.X.': Pq ser Fake? Muitos usam fake, pq não quer se expor ou [expor] a familia, ou pq a [sic] muito preconceito, ou pq a familia tem vergonha... pelo amor de Deus né. [...] DIGA NÃO AO PRECONCEITO... SE ACEITE, SE ASSUMA, MOSTRA Q É CAPAZ DE FAZER COISAS Q OS [que] SE JULGAM "NORMAIS" NÃO CONSEGUEM..."

${ }^{5}$ A teoria das faces, desenvolvida por Penelope Brown e Stephen Levinson, aborda a interação social na perspectiva dos atos de fala (Austin e Searle) e o impacto que esses atos teriam na face positiva ou na face negativa de cada interlocutor. A face positiva deriva da necessidade de ser apreciado e reconhecido pelo outro; por sua vez, a face negativa advém da necessidade de defesa de seu espaço pessoal. Nessa perspectiva, a interação social bem-sucedida é aquela que preserva ambas as faces dos interlocutores. Por meio da função-avatar, um sujeito-autor consegue ameaçar as faces do sujeitoleitor, sem colocar em riscos suas faces. Na verdade, ele arrisca somente as faces de seu avatar. Para maiores informações sobre a teoria das faces, consulte Introdução à linguística de José Fiorin (2002).

${ }^{6}$ Para preservar a identidade dos internautas, nenhum nome será divulgado neste trabalho.

${ }^{7}$ Disponível em: <http://www.orkut.com.br/Main\#CommMsgs? cmm= $2527736 \&$ tid $=5327817380699100583>$. Acesso em: 23 nov. 2010. Grifos da autora. 
X.X., a autora do comentário acima, publicado numa comunidade virtual, expressa sua opinião contrária ao uso dos fakes, isto é, o avatar que muitas pessoas assumem ao publicar suas opiniões no fórum da comunidade. Segundo ela, muitos usam fake, porque não querem se expor ou ser vítima de preconceito. Em termos pragmáticos, não querem arriscar a própria face.

$\mathrm{Na}$ verdade, o fake e avatar permitem um efeito de dissimulação que ocorre entre a função-avatar, um eu "virtual" do sujeito-autor e o leitor virtual, que é "constituído no próprio ato da escrita, [...] aquele que o autor imagina (destina) para seu texto e para quem ele se dirige" (ORLANDI, 2000 , p. 9). Assim, ao assumir a função-avatar, o sujeito-autor procura esconder um conflito entre sua posição-sujeito e a posição-sujeito do leitor virtual. Essa é sempre uma relação imaginária, pois o leitor virtual é da ordem das formações imaginárias do sujeito-autor; em outras palavras, o leitor virtual é aquele a quem o sujeito-autor imagina se dirigir. Por essa razão, todo processo de escrita e leitura revela o jogo determinado entre o leitor virtual e o leitor real. Todo leitor real relaciona-se obrigatoriamente com o leitor virtual, constituído imaginariamente no texto pelo sujeito-autor. A SD é o resultado do relacionamento entre X.X., como leitora real dos textos assinados por avatares, e o leitor virtual. De acordo com Schons (2009, p. 175), "no movimento da língua com a história é dada a perceber a irrupção do sujeito-autor no discurso que materializa, linguisticamente, aquilo que deseja manter em suspenso e que pode vir a ser pensado pelo leitor", tal como a função-avatar e o entendimento que ele faz enquanto autor. No exemplo em questão, há deslizamento em relação ao fake e aos espaços de sua circulação (família, sociedade), liberdade e liberação, normalidade e anormalidade.

Antes de darmos um efeito de conclusão a este artigo, julgamos necessário trazer mais um exercício de análise, a fim de enriquecermos toda a discussão em torno da função-avatar.

Selecionamos um recorte discursivo do fórum de discussão do site stormfort.org, cujos organizadores se declaram como "uma comunidade de Brancos Nacionalistas. Existem milhares de organizações que promovem 
os interesses, valores e herança de não-Brancos. Nós promovemos os nossos". 8

Nosso post é a resposta do avatar "Panico88" para a pergunta-tema “Os negros são os verdadeiros racistas?", postada pelo avatar “Klein”, ambos membros da comunidade stormfront.

Vejamos o que Pânico88 escreve:

Todos no mundo são racistas, o problema é que só mostram isso em nossa raça, é a que mais se destaca no mundo logo também é a que mais leva porrada.

Mas mal sabem eles que só estão piorando o racismo para todos os lados, pelo nosso lado só nos deixam com raiva por essa perseguição e notoriedade, pelas demais a impunição, podem ser racistas a vontade que o máximo que se faz é elogiar.

Negros são extremamente limitados, qualquer coisa que surgir tem que agarrar como se fosse suas próprias vidas, e em casos é, logo essa oportunidade de ser vitimizado e ganhar com isso é tudo que eles querem. Os judeus fazem o mesmo só que melhor.

"We must secure the existence of our people and a future for white children 14/88".

O cibernauta que se camufla sob o avatar "Pânico88" expressa, por meio deste, opiniões que não revelaria em público, sob pena de sofrer sanções jurídico-criminais, pois racismo é crime no Brasil. O discurso de Pânico88 inscreve-se na FD eugenista, que defende a superioridade de uma raça em relação às outras. É essa mesma FD que alimentou o discurso nazista da máquina de guerra hitleriana. Pânico88 escreve que "negros são extremamente limitados" e "judeus fazem o mesmo só que melhor". O caráter eugenista de Pânico88 aparece no rodapé de suas mensagens: "Nós precisamos garantir a existência de nosso povo e o futuro das crianças brancas". A ideologia eugenista ensina que a "raça superior" deve se multiplicar e suplantar as "raças inferiores". No caso de Pânico88, a ideia seria de multiplicar a raça

${ }^{8}$ A community of White Nationalists. There are thousands of organizations promoting the interests, values and heritage of non-Whites. We promote ours. Disponível em: <www.stormfront.org>. Tradução nossa. 
branca, "assegurando o futuro das crianças brancas", e suplantar as raças inferiores, isto é, os "negros extremamente limitados e judeus".

No discurso do avatar Pânico88 o não dito se faz presente. De certa forma, por se filiar à FD eugenista, o discurso de Pânico88 prega a defesa do extermínio racial ou higineização étnica como meio de "assegurar a existência do povo branco e o futuro das crianças brancas”. Isso se mostra ainda mais evidente quando Pânico88 sentencia: "Mas mal sabem eles que só estão piorando o racismo para todos os lados, pelo nosso lado só nos deixam com raiva por essa perseguição e notoriedade..." O extermínio do não branco seria justificado pela "raiva" que negros suscitam nos brancos. Conforme o discurso desse avatar, negros e brancos são tratados com desigualdade: "todos no mundo são racistas, o problema é que só mostram isso em nossa raça, é a que mais se destaca no mundo logo também é a que mais leva porrada". O sujeito indeterminado da oração "só mostram isso em nossa raça” pode se referir à mídia, à opinião pública ou à sociedade brasileira em geral.

A inscrição do discurso de Pânico88 à FD eugenista fica clara no próprio nome do avatar Pânico88. A pronúncia inglesa do algarismo 88 pode ser transcrita pelas letras $\mathrm{HH}$, que constitui uma abreviação de "Heil Hitler", o que confirma a ideologia nazista representada pela suástica no rodapé do post. "Pânico" parece remeter ao horror do Holocausto judeu e à limpeza étnica presente no discurso de Pânico88 por meio do não dito.

$\mathrm{O}$ uso de um avatar parece denunciar a autocensura que o cibernauta impõe a si mesmo no hiperdiscurso. Mais uma vez, podemos ver que a função-avatar é mais do que um simples pseudônimo literário; é a existência pretensamente livre de um sujeito-autor no ciberespaço. Ao assumir a funçãoavatar, o cibernauta pretende ser livre para dizer "aquilo que não convém dizer".

\section{Considerações Finais}

Diante de tudo o que foi posto, pode-se afirmar que a função-avatar é um dos processos de silenciamento de si no hiperdiscurso. Por não ser uma disciplina fechada, canônica, a AD constrói-se a cada nova análise. A teoria e a análise se retroalimentam, o que torna possível a formulação de novas hipóteses que o analista julga ser útil para a análise do corpus de seu trabalho. Esse é o caso da função-autor-avatar. 
Algumas questões permanecem em aberto e requerem novas pesquisas e discussões:

1. A função-avatar pode denunciar uma autocensura no hiperdiscurso? Em outros termos, o sujeito do hiperdiscurso lança mão de avatares para expor discursivamente aquilo que ele mesmo censura em seu discurso?

2. Quais são as implicações da função-avatar sobre o conceito de sujeito e de autoria?

Aí está a delícia de transitar pelos saberes da AD: a cada novo "fim" vislumbramos "novos" inícios ou reinícios. Celebramos o "fim" deste artigo brindando o "início" de novos trabalhos, não em função-avatar, mas buscando, talvez, construir "uma instância de saber" que adquira um sentido diferente de serialização e que também, enquanto sujeito-autor, pretende se ver livre de amarras institucionais e de seus sistemas de controle, sobretudo em instâncias de pesquisa.

\section{Referências}

CASTELLS, M. A galáxia da internet: reflexões sobre a internet, os negócios e a sociedade. Tradução Maria L. de A. Borges. Rio de Janeiro: Jorge Zahar, 2003.

CAZARIN, E. A. Texto e hipertexto: processos de leitura. In: SCHONS, C. R.; CAZARIN, E. A. (Orgs.). Lingua, escola e mídia: entrelaçando teorias, conceitos e metodologias. Passo Fundo: UPF Editora, 2011.

FIORIN, J. L. A linguagem em uso. In: FIORIN, J. L. Introdução à linguística I: objetos teóricos. São Paulo: Contexto, 2002. p. 165-186.

FOUCAULT, M. A ordem do discurso. São Paulo: Loyola, 1999 [1971].

FUKUE, M. R. Y. De um pólo a outro: análise de discursividades sobre transtorno afetivo bipolar em espaços eletrônicos. 2011. Dissertação (Mestrado em Letras) - Universidade de Passo Fundo, Passo Fundo. 2011.

${ }^{9}$ Reportamo-nos a Nunes (2011). 
GALLO, S. L. Sobre a estrutura e o evento. In: GALLO, S. L. Texto: como apre(e)nder esta matéria? Análise discursiva do texto na escola. 1994. Tese (Doutorado em Linguística) - Universidade Estadual de Campinas, Campinas. 1994.

GALLO, S. L. Como o texto se produz: uma perspectiva discursiva. Blumenau: Nova Letra, 2008.

GRIGOLETTO, E. A autoria no hipertexto. Hipertextus, Recife-PE, n. 2, p. 1-13, jan. 2009. Disponível em: <http://www.hipertextus.net/ volume2/Evandra-GRIGOLETTO'pdf>. Acesso em: 15 ago. 2011.

GRIGOLETTO, E.; JOBIM, A. P. A busca da identidade pela/na escrita virtual: uma análise de blogs "antipeso". In: RETTENMAIER, M.;

RÖSING, T. M. K. (Orgs.). Questões de leitura no hipertexto. Passo Fundo: UPF Editora, 2007. p. 64-91.

LÉVY, P. As tecnologias da inteligência: o futuro do pensamento na era da informática. Rio de Janeiro: Editora 34, 1993.

LÉVY, P. O que é o virtual? Tradução de Paulo Neve. São Paulo: Editora 34, 1996.

LÉVY, P. Cibercultura. Tradução de Carlos Irineu da Costa. São Paulo: Editora 34, 1999.

NUNES, J. H. Uma revista de Língua Portuguesa: divulgação de saberes e silêncios. In: SCHONS, C. R; CAZARIN, E. A. (Orgs.). Lingua, escola e midia: entrelaçando teorias, conceitos e metodologias. Passo Fundo: UPF Editora, 2011.

ORLANDI, E. P. Interpretação: autoria, leitura e efeitos do trabalho simbólico. Petrópolis: Vozes, 1996a.

ORLANDI, E. P. A linguagem e seu funcionamento: as formas do discurso. 4. ed. Campinas: Pontes, 1996b.

ORLANDI, E. P. Discurso e leitura. 5. ed. São Paulo: Cortez; Campinas: Unicamp, 2000. 
ORLANDI, E. P. Discurso e texto: formulação e circulação dos sentidos.

Campinas: Pontes, 2001.

PÊCHEUX, M. Ler o arquivo hoje. In: ORLANDI, E. P. et. al. (Orgs.). Gestos de leitura: da história no discurso. Homenagem a Denise Maldidier. 2. ed. Campinas: Editora da UNICAMP, 1997.

SCHONS, C. R. Escrita, efeito de memória e produção de sentidos. In: SCHONS, C. R.; RÖSING, T. M. K. (Orgs.). Questões de escrita. Passo Fundo: Editora UPF, 2005. p. 138-156.

SCHONS, C. R. Quem é o sujeito no espelho da gramática? Desenredo, Passo Fundo, v. 5, n. 2, p. 170-181, jul./dez. 2009. 